\title{
Functional outcome assessment of frozen shoulder treated by distension hydrodilatation and viscosupplementation: A prospective study
}

\author{
Krishna Subramanyam ${ }^{1}$, Sameer Chaitanya Sahini ${ }^{*}$, Satish Kumar ${ }^{3}$, Prasad Raju Ampajwalam ${ }^{4}$ \\ Dept. of Orthopaedics, Yashoda Hospital, Hyderabad, Telangana, India
}

*Corresponding Author: Sameer Chaitanya Sahini

Email: sameerchaitanyasahini@gmail.com

\begin{abstract}
Purpose: The purpose of this study is to assess the role of distension hydrodilatation and viscosupplementation of the glenohumeral joint in the management of frozen shoulder.

Materials and Methods: A total of 50 Patients suffering with frozen shoulder presented to Yashoda hospital, malakpet, Hyderabad. All patients were treated by distension hydrodilatation and viscosupplementation under fluoroscopy (C-ARM) guidance as a day care procedure. The study period was from August 2018 to February 2019. All the patients were followed-up for a minimum period of 6 months to maximum 1 year. The mean age of the study group was 45.86 years.

Results: All cases were assessed by oxford shoulder score (OSS) and visual analogue score (VAS) pre-procedure and post-procedure. All the patients regained near normal to normal shoulder movements in all directions by the end of $3^{\text {rd }}$ week. Complete pain relief was seen by 2 weeks following the procedure. There was decrease in Oxford Shoulder Score (OSS) by mean of 18.22 (pre-procedure was 31.34 and postprocedure was 13.12), Visual Analogue Scale (VAS) mean was also decreased from 8.42 to 1.14. 43 of 50 patients obtained full free range of movements. Remaining 7 patients had restriction of terminal rotational movements, 3 of 7 patients had restriction of $10^{0}$ of external rotation, 4 of 7 had restriction of $10^{\circ}$ of internal rotation.

Conclusion: Distension hydrodilatation and viscosupplementation is a definitive treatment modality in patients with frozen shoulder. It results in significant and sustained relief of pain and also results in regaining of full range of shoulder movements.
\end{abstract}

Keywords: Frozen shoulder, Distension hydrodilatation, Viscosupplementation.

\section{Introduction}

Frozen shoulder ${ }^{1}$ also known as adhesive capsulitis or periarthritis shoulder, is a condition characterized by pain and stiffness of shoulder joint. Frozen shoulder affects approximately $2-5 \%$ of the population. ${ }^{1}$ Frozen shoulder typically affects the rotator interval and coracohumeral ligament, which causes early restriction of external rotation. ${ }^{2}$ As the disease progresses, glenohumeral capsule is contracted and glenohumeral ligaments thickened. ${ }^{3}$ Night pain with a reduced range of movement, particularly external rotation is one of the cardinal symptoms ${ }^{3}$ of frozen shoulder. It may be idiopathic or secondary to preceding trauma. It has female preponderance and has strong association with diabetes mellitus. ${ }^{4}$ Frozen shoulder is usually self-limiting, typically lasting between 12 months and 36 months with spontaneous resolution, although some studies demonstrate up to $41 \%$ of patients had persisting symptoms associated with pain and functional loss. Treatment methods for the management ${ }^{5}$ of adhesive capsulitis are broad, they include medical treatment and physiotherapy, manipulation under anaesthesia, arthroscopic $360^{\circ}$ capsular release, intra-articular steroid injections and distension hydrodilatation of the shoulder joint (either by fluoroscopy or ultrasound guidance). ${ }^{6-8}$

Distension of the shoulder joint capsule was attempted by injecting contrast medium or saline solution under pressure was described by ANDREN and LUNDBERG (1965).

In distension hydrodilatation ${ }^{8-10}$ the shoulder joint capsule distended by injecting a substantial amount (80$100 \mathrm{ml}$ ) of normal saline into the joint. It distends joint capsule with capsular rupture as the desired endpoint.
Pathophysiological increased glycosaminoglycan concentration seen in the joint capsule in frozen shoulder promotes myofibroblast activity and this is reversed by the joint distension. ${ }^{7}$ It is technically easy to perform and it is minimally invasive. Hydrodilatation is more effective than physiotherapy and it is also without complications like iatrogenic proximal humerus, rotator cuff tears, glenohumeral ligament tears, labral tears, osteochondral fractures occurred by manipulation under anaesthesia. ${ }^{11}$ Arthroscopic $360^{\circ}$ capsular release is an effective method but it is more invasive and expensive. ${ }^{12}$ Some studies ${ }^{9,10,14}$ have suggested an improvement of pain and movements following hydrodilatation and steroid injections. In our study we managed frozen shoulder by distension hydrodilatation and viscosupplementation (inj.Synviscone).

\section{Materials and Methods}

A prospective study was carried out from August 2018 to February 2019, a total number of 50 patients who diagnosed clinically as frozen shoulder and confirmed by high resolution ultrasound (HRUS) (Fig. 1a \& 1b) were treated by distension hydrodilatation and viscosupplementation followed by 6-12weeks of physiotherapy (in terms of progressive, active assisted and active ROM shoulders in all directions followed by strengthening of various muscles around shoulder). The inclusion criteria were patients with painful restriction of active and passive shoulder movements, after failed conservative management for a minimum period of 3 months, worsening of symptoms even after physiotherapy and steroid injections, patients with already complete restriction of movements with less pain component. All the patients in this study had idiopathic frozen shoulder. 
The exclusion criteria include shoulder stiffness in postinfective cases; rotator cuff tears, post fracture and Postsurgery around the shoulder. Following the procedure all 50 patients were followed-up for a minimum period of 6 months and maximum period of 1year, none of the patients lost to follow-up. Among the 50 patients, 20 were male and 30 were female. 28 patients were associated with type 2 diabetes mellitus. The mean age of study group (patients) was 45.86 years (range 30 to 60years). The average procedure duration was 15 minutes.
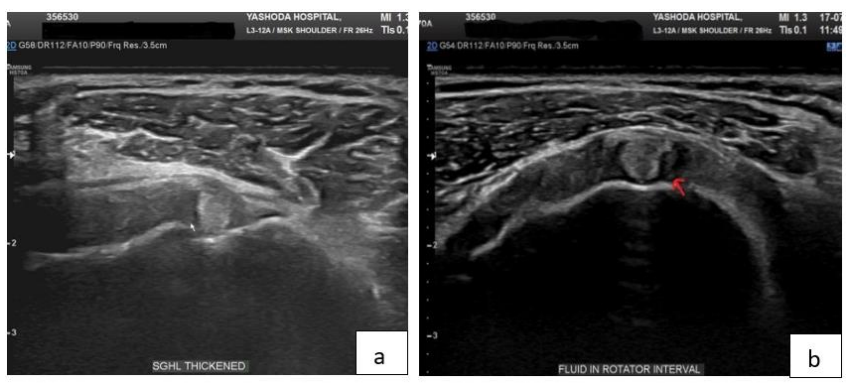

Fig 1a \& 1b: Ultrasound images showing thickened SGHL and hypo echoic thickening of rotator interval (red arrow) suggestive of periarthritis shoulder or frozen shoulder.

\section{Procedure technique}

Patient in supine position, under short general anaesthesia, with a folded towel under the scapular body, a 22 gauge spinal needle was passed into the gleno-humeral joint. The needle position was confirmed under fluoroscopy ${ }^{13}$ guidance, an injection of $2.5 \mathrm{ml}$ of non-ionic contrast material (OMNIPAQUE 350) was passed to confirm that the needle is completely intra-articular (Fig. 2b). Then 80-100 ml normal saline was injected into gleno-humeral joint. In most of cases while pushing the normal saline we observed distension of joint fluoroscopically (Fig. 2c) and clinically palpable click sounds due to stretching of joint capsule. ${ }^{14}$ Then shoulder was moved through smooth arc of movements in all directions while the assistant stabilizing the scapula blade, in a sequential manner without any manipulation throughout the procedure (Fig. 2d-2h). This was followed by injecting inj. HYLAN-GF 20 (injection Synviscone $8 \mathrm{mg} / \mathrm{ml})^{15,16}$ into the gleno humeral joint. Post-procedure initial 24 hours the shoulder was immobilized. From the $2^{\text {nd }}$ day the shoulder was mobilized and progressive physiotherapy was carried out.

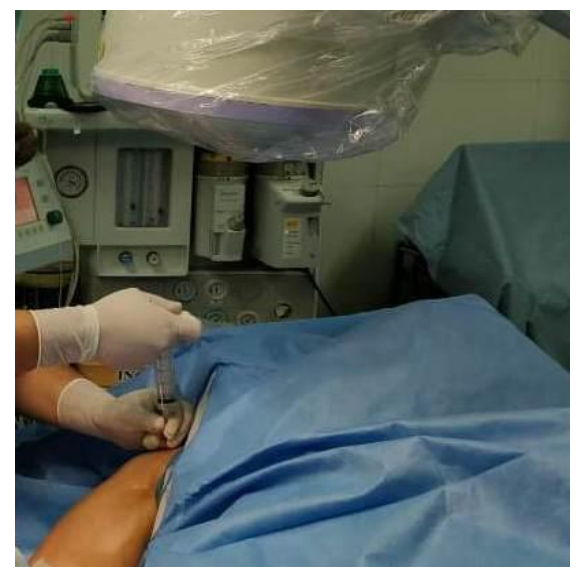

Fig. 2a: Placement of needle

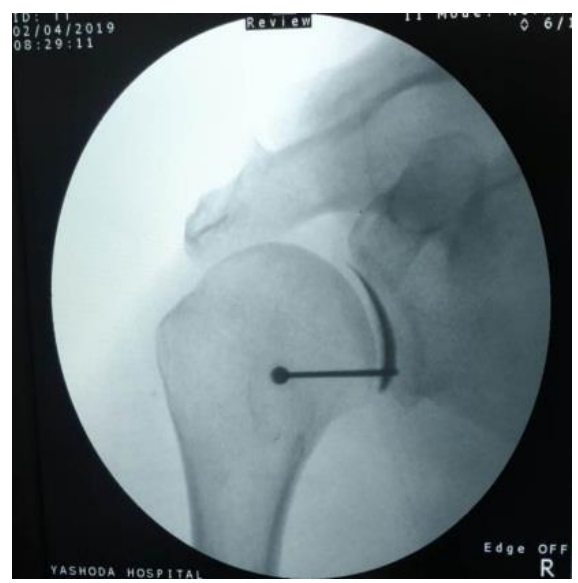

Fig. 2b: C-ARM image - Arthrography

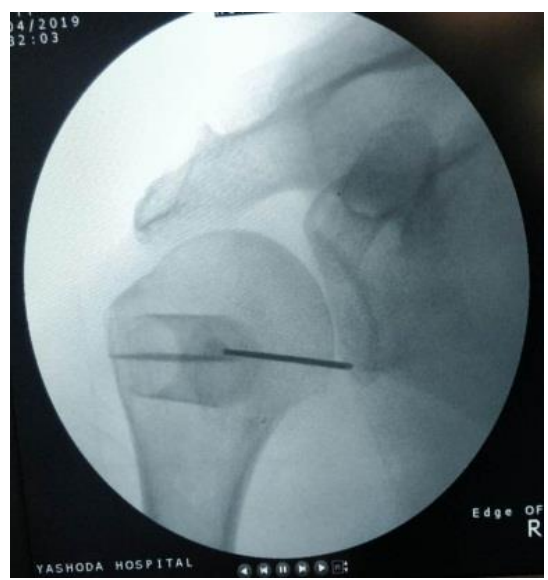

Fig 2c: Image showing distension of shoulder 


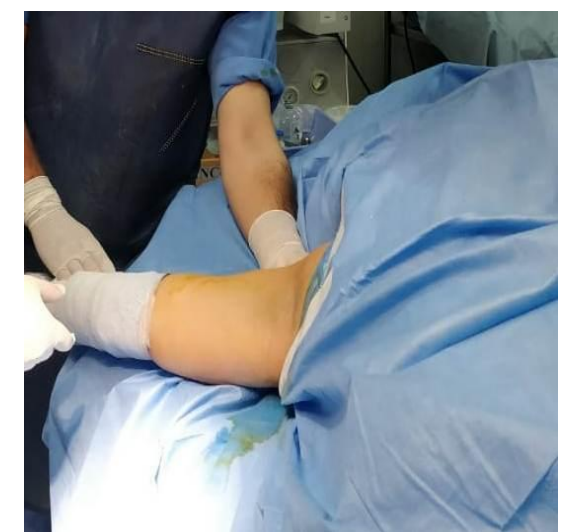

Fig. 2d: Abduction range of movement

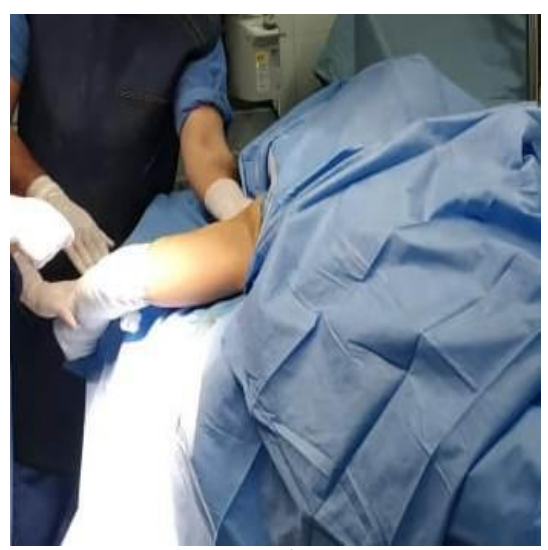

Fig. 2e: External rotation in $90^{\circ}$ abduction

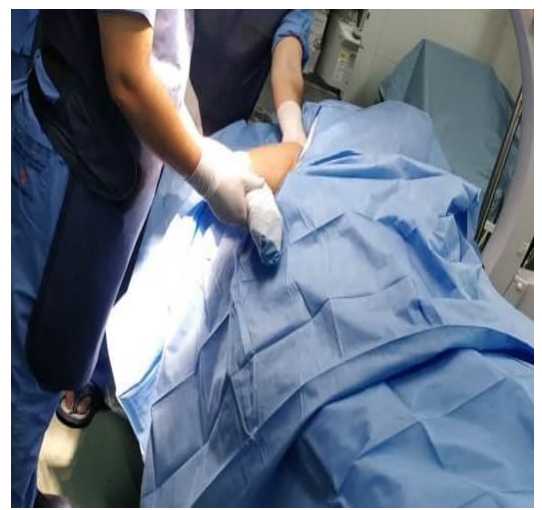

Fig. 2f: internal rotation in $90^{\circ}$

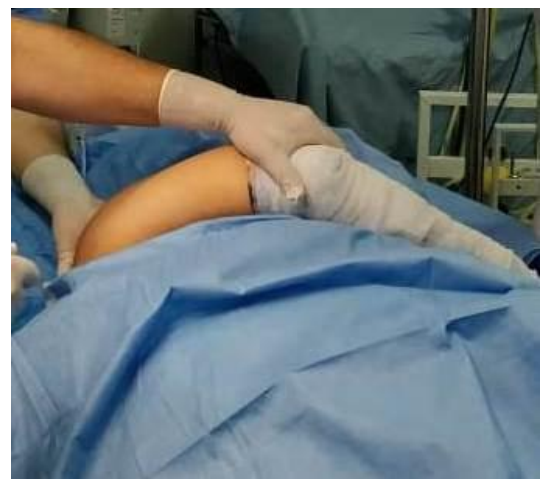

Fig. 2g: Complete adduction

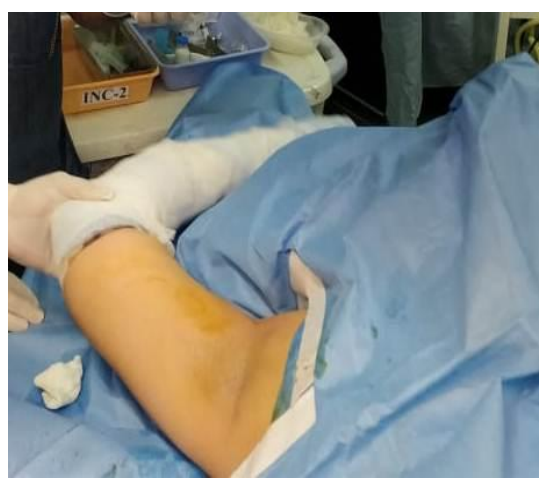

Fig. 2h: Complete abduction

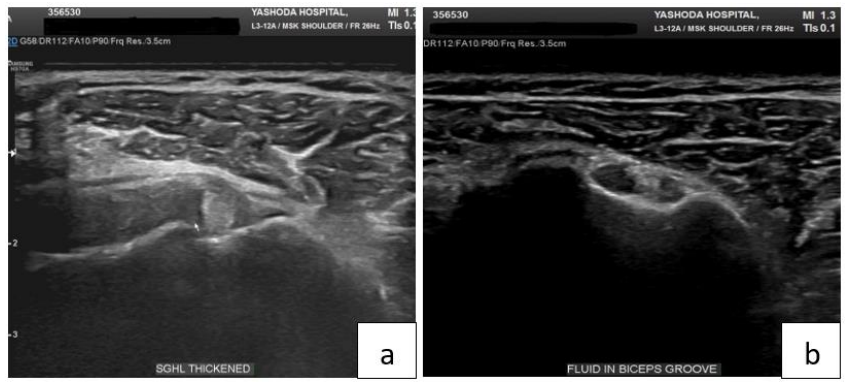

Fig. 3a \& 3b: Pre-procedure USG images showing thickened superior gleno humeral ligament and fluid in biceps groove.
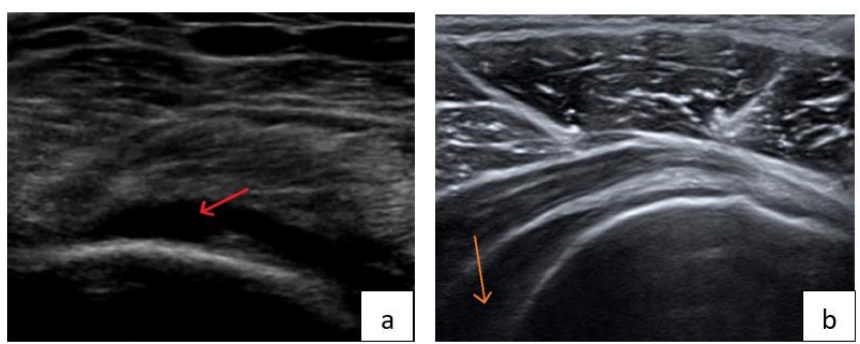

Fig. 4a \& 4b: Immediately after distension hydrodilatation USG images shows distended gleno-humeral joint and distended posterior recess (red and orange arrows).
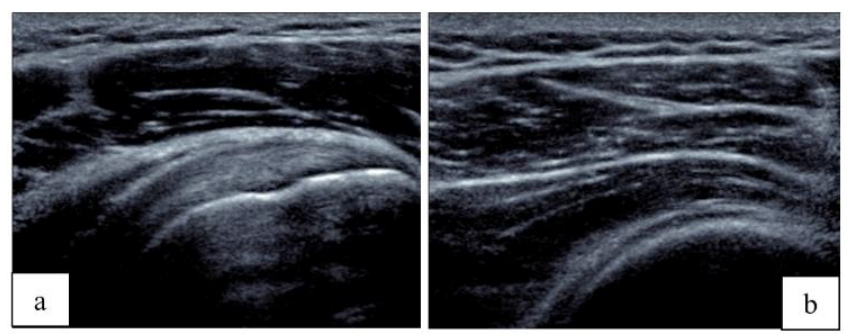

Fig 5a \& 5b: Follow-up USG images showing normal supraspinatus and infraspinatus with well-maintained glenohumeral joint line.

\section{Results}

A total of 50 patients with frozen shoulder underwent distension hydrodilatation and viscosupplementation, with post-procedure physiotherapy. The mean age of study group was 45.86 years (range 30 years to 60 years), 30 were female and 20 were male, and 28 patients were associated with type 2 diabetes mellitus. We observed decrease in the intensity of 
pain as early as $2^{\text {nd }}$ day following the procedure and complete relief of pain by the end of $2^{\text {nd }}$ week. Shoulder range of movement initiated from $2^{\text {nd }}$ of post procedure in sequential manner i.e. assisted active range of movements followed by active range of movements and strengthening of perishoulder musculature over a period of 2-3 weeks. 43 patients regained full range of movements. Remaining 7 patients had terminal restriction of movements, out of them 3 patients had restriction of $10^{0}$ of external rotation, 4 had restriction of 10 ${ }^{0}$ of internal rotation. These 7 patients were associated with type 2 diabetes. All the patients were able to do their normal routine activities.

Pre-procedure OSS (mean 31.34) and VAS scores (mean 8.42) were functionally worse at the time of presentation. A significant improvement in functional scores was demonstrated at the end of $3^{\text {rd }}$ week of post-procedure, with the mean oxford shoulder score (OSS) post-procedure was 13.12 (decreased by 18.22) and the mean VAS score was also reduced from 8.42 to 1.14 . No recurrence of shoulder stiffness and any other complications during or postprocedure were noted.

Graph 1: Showing gender incidence

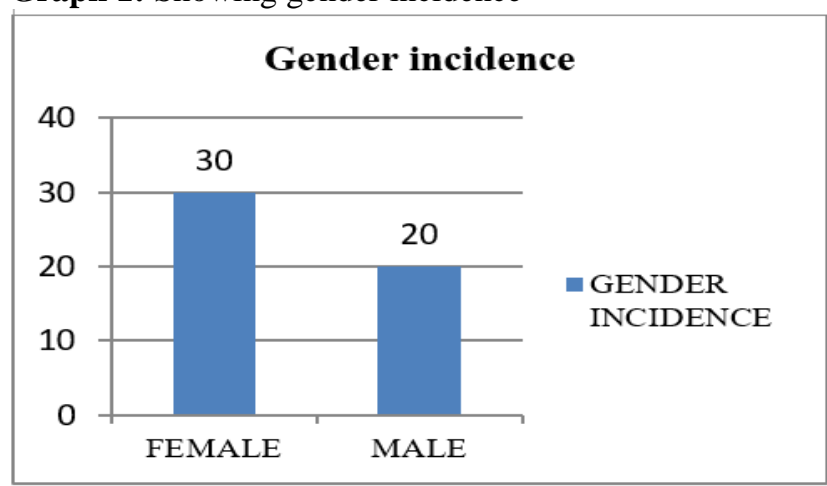

Table 1: Showing pre-procedure shoulder movements.

\begin{tabular}{|c|c|c|c|c|c|}
\hline \multicolumn{2}{|c|}{ Pre- procedure abduction } & \multicolumn{2}{c|}{ Pre-procedure external rotation } \\
\hline ROM & $\begin{array}{c}\text { Number of } \\
\text { patients }\end{array}$ & $\begin{array}{c}\text { Percentage } \\
(\%)\end{array}$ & ROM & $\begin{array}{c}\text { Number of } \\
\text { patients }\end{array}$ & Percentage (\%) \\
\hline $0-50^{0}$ & 6 & 12 & $0-15^{0}$ & 9 & 18 \\
\hline $0-70^{0}$ & 31 & 62 & $0-20^{0}$ & 18 & 36 \\
\hline $0-100^{0}$ & 13 & 26 & $0-30^{0}$ & 23 & 46 \\
\hline
\end{tabular}

Table 2: Showing post-procedure limitation of shoulder movements in patients

\begin{tabular}{|c|c|c|}
\hline Movements & Post-Procedure ROM & Number of patients (50) \\
\hline Abduction & No limitation & All \\
\hline Internal rotation & $10^{0}$ limitation & 04 out of 50 \\
\hline External rotation & $10^{0}$ limitation & 03 out of 50 \\
\hline Forward flexion & No limitation & All \\
\hline Extension & No limitation & All \\
\hline Adduction & No limitation & All \\
\hline
\end{tabular}

Table 3: Showing statistical analysis, OSS- oxford shoulder score
Graph 2: Showing age distribution in this study

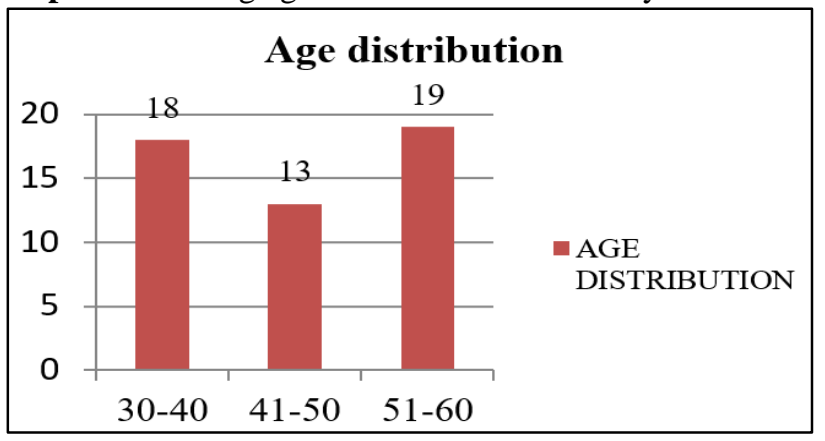

Graph 3: Pie chart showing patients associated with type2 diabetes mellitus

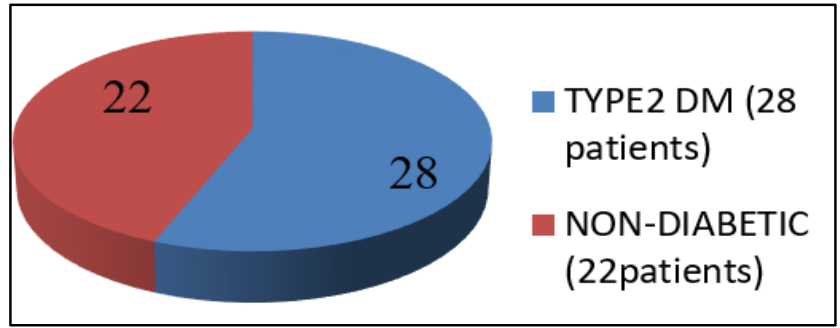

Graph 4: Showing functional outcome of procedure assessed by OSS (OXFORD SHOULDER SCORE, 12-60) and VAS (VISUAL ANALOGUE SCALE, 0-10).

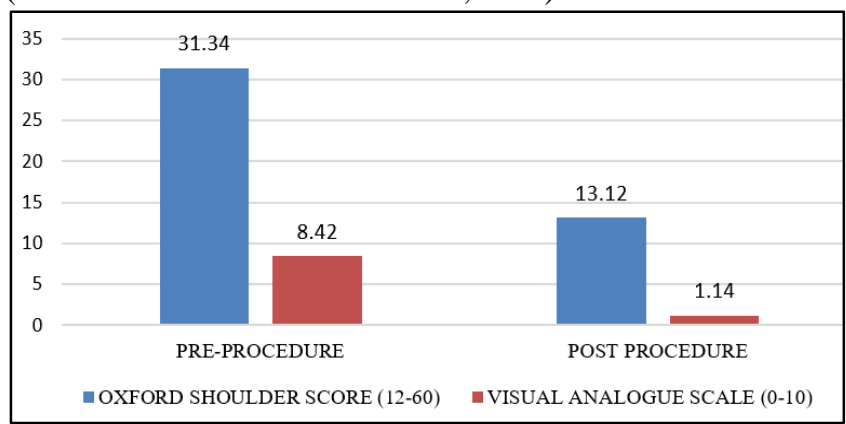




\begin{tabular}{|l|l|c|c|c|c|c|}
\hline \multicolumn{2}{|c|}{} & Mean & N & Std. Deviation & T Test & P Value \\
\cline { 1 - 7 } Paired Sample T Test & PRE-OSS & 31.32 & 50 & 8.948 & 16.91 & 0.001 \\
\cline { 2 - 5 } & POST-OSS & 13.02 & 50 & 1.974 & & \\
\hline
\end{tabular}

Table 4: Showing correlations for pre-OSS and post- OSS, OSS- oxford shoulder score

\begin{tabular}{|c|c|c|c|}
\hline \multicolumn{4}{|l|}{ Correlations } \\
\hline & & PRE-OSS & POST-OSS \\
\hline \multirow[t]{2}{*}{ PRE-OSS } & Pearson Correlation & 1 & $0.721^{* *}$ \\
\hline & P Value & & 0.001 \\
\hline \multirow[t]{2}{*}{ POST-OSS } & Pearson Correlation & $0.721^{* *}$ & 1 \\
\hline & P Value & 0.001 & \\
\hline
\end{tabular}

Correlation and significance is calculated for pre and post OSS which showed a positive correlation $r=0.721(\mathrm{r}=$ Pearson correlation Coefficient) - Indicates a correlation and the $\mathrm{p}$ - value is $<0.05$ which is significant.

Correlation and regression analysis between DM and post procedural ROM shows an absence of correlation $\mathrm{r}=0$ indicating absence of correlation and $\mathrm{P}$ - value is 1 which indicates that there is no significance.

Table 5: Showing comparison of different studies

\begin{tabular}{|c|c|c|c|c|}
\hline Study & Patients & Used material & $\begin{array}{l}\text { Number of } \\
\text { injections }\end{array}$ & Outcome \\
\hline $\begin{array}{l}\text { Rajendranath et } \quad \mathrm{al}^{8} \\
\text { (2017) }\end{array}$ & 118 & Normal Saline, corticosteroid & Single & Good \\
\hline Clement et $\mathrm{al}^{18}(2013)$ & 57 & 40ml saline, steroid, local anaesthetic & Single & $62.71 \%$ \\
\hline Tveita et $\mathrm{al}^{19}(2008)$ & 62 & 10ml saline, steroid, local anaesthetic & $\begin{array}{c}3 \text { injections at } 2 \\
\text { weeks interval }\end{array}$ & $64.51 \%$ \\
\hline Quraishi et al ${ }^{11}$ (2007) & 19 & $\begin{array}{l}\text { Various amounts of saline, } 30 \mathrm{mg} \text { steroid, } \\
\text { local anaesthetic }\end{array}$ & single & $81 \%$ \\
\hline Vad VB et $\mathrm{al}^{21}(2003)$ & 22 & $60 \mathrm{ml}$ saline & Single & $86.36 \%$ \\
\hline Gavant et $\mathrm{al}^{20}(1994)$ & 16 & 30ml saline, steroid, local anaesthetic & Single & $87.50 \%$ \\
\hline Jacob's et al ${ }^{17}(1991)$ & 47 & 20ml saline, steroid, local anaesthetic, air & $\begin{array}{l}3 \text { injections at } 6 \\
\text { weeks interval }\end{array}$ & $82 \%$ \\
\hline Our study & 50 & $\begin{array}{c}\text { 80-100 ml saline, viscosupplementation } \\
\text { (HYLAN GF20) }\end{array}$ & Single & $86 \%$ \\
\hline
\end{tabular}

\section{Discussion}

Frozen shoulder ${ }^{1,2}$ is characterised by pain and stiffness of the shoulder with restriction of active and passive shoulder movements and results in functional disability and thus affecting the activities of daily living. The aetiology of frozen shoulder is unknown, some studies reported pathophysiological similarity to Dupuytren's contracture. ${ }^{3}$ Some studies reported resolution of the frozen shoulder often takes up to 2 to 3 years and even more. ${ }^{3}$ We managed all frozen shoulder patients by distension hydrodilatation and viscosupplementation ${ }^{15,16}$ under fluoroscopy guidance as a day care procedure. It is minimally invasive radiological intervention. Distension hydrodilatation ${ }^{6-8}$ works by the injected fluid into the shoulder joint under pressure will distends the joint volume by disrupting the adhesions and scar tissue and thereby improves range of movements of shoulder. Some studies ${ }^{8-10}$ reported that they infused normal saline and corticosteroid; some studies have used air ${ }^{17}$ instead of saline.
We distended shoulder joint capsule by injecting 80-100 $\mathrm{ml}$ normal saline combined with injection HYLAN GF 20 (inj. Synviscone $8 \mathrm{mg} / \mathrm{ml})^{10,12}$ under fluoroscopy guidance. HYLAN GF 20 (inj. Synviscone) is an elastoviscous fluid contains hylan A and hylan B polymers produced from chicken combs. Hyaluronan is a chemically cross linked high molecular weight long-chain polymer containing repeating disaccharide units of sodium-glucuronate-N-acetyl glucosamine. HYLAN GF20 elasticity and molecular weight is similar to the molecular weight and elasticity of the natural lubricants in the joints of young people. Inj.Synviscone reduces pain and improves shoulder function. ${ }^{13}$ Adverse effects rarely seen after inj.Synviscone ( $<2 \%$ incidence), it includes pain, swelling, heat, and redness, fluid accumulation in or around the joint.

Average time taken for procedure was 15 minutes. Postprocedure Shoulder range of movement initiated from $2^{\text {nd }}$ day of post procedure in sequential manner i.e. assisted active range of movements followed by active range of movements and strengthening of peri-shoulder musculature over a period 
of 2-3 weeks. We observed decrease in the intensity of pain as early as $2^{\text {nd }}$ day following the procedure and complete relief of pain by the end of $2^{\text {nd }}$ week. Clinical outcomes of the present study showed an $86 \%$ (43 of 50 patients) success rate regarding attained full range of shoulder movements with no recurrence of stiffness. In remaining $14 \%$ (7 of 50 patients), 3 patients had restriction of $10^{\circ}$ of external rotation, 4 had restriction of $10^{\circ}$ of internal rotation. Clinical results were favourable, even when the average follow- up was short (6 months to 1 year). Clinical outcomes in diabetic patients also showed improvement. All patients were able to do their regular activities like combing hair and to reach objects above head level. No complications occurred during or postprocedure in our study.

Rajendranath et $\mathrm{al}^{8}$ study (2017) reported distension hydrodilatation in 118 cases with frozen shoulder had significant functional improvement after procedure. Quraishi et al study ${ }^{11}$ (2007) reported post-hydrodilatation outcomes in 19 patients with $81 \%$ patients get near shoulder function. For distension he used $20 \mathrm{ml}$ saline, $30 \mathrm{mg}$ steroid and local anaesthetic.

Clement et al study ${ }^{18}$ (2013) reported posthydrodilatation outcomes in 51 patients with a mean followup of 14 months. For distension of shoulder he used saline $40 \mathrm{ml}$ and mixture of triamcinolone and lignocaine. $62.74 \%$ of patients (32 of 51) get normal or near-normal shoulder function as assessed by the Oxford Shoulder Score. One patient developed septic arthritis after hydrodilatation. This study shows similar outcome in diabetic patients.

Tveita et al study ${ }^{19}$ (2008) reported good outcome in 40 of $62(64.51 \%)$ patients, for distension he used $10 \mathrm{ml}$ saline, local anaesthetic and steroid. He gave 3 injections at 2 week intervals.

Gavant et $\mathrm{al}^{20}$ (1994) reported that $87.50 \%$ (14 of 16) patients experienced immediate pain relief and increased range of motion after infiltration of $30 \mathrm{~mL}$ of mixture of saline, lidocaine and corticosteroids.

Jacob's et al study ${ }^{17}$ (1991) reported post-hydrodilatation outcomes in 47 patients with $82 \%$ patients get near shoulder function. For distension he used $20 \mathrm{ml}$ saline, steroid and local anaesthetic. In this study he gave 3 injections at 6 week intervals.

In a prospective ${ }^{21}$ study (2003) by Vad VB, Sakalkale D, Warren RF, 22 patients underwent capsular distension followed by a physiotherapy program followed for a period of one year. 19 patients showed an improved range of motion $(86.36 \%)$. The three patients without significant improvement had more severe disease at the time of intervention.

In our study we infused $60-80 \mathrm{ml}$ normal saline and injection Synviscone $8 \mathrm{mg} / \mathrm{ml}$ for distension of shoulder joint in 50 patients, $86 \%$ (43 of 50) patients experienced pain relief and get normal shoulder movements, out of remaining 7, 3 patients had restriction of $10^{\circ}$ of external rotation, 4 patients had restriction of $10^{\circ}$ of internal rotation, all these 7 patients were associated with type 2 diabetes. A significant improvement in functional scores was present with oxford shoulder score (OSS) pre-procedure mean was 31.34 post- procedure mean was 13.12 (decreased by 18.22) and the VAS score mean was also reduced from 8.42 to 1.14 . None of the patients had any complications during or post-procedure.

\section{Conclusion}

Distension hydrodilatation and viscosupplementation injection HYLAN GF20 (inj. Synviscone) is a definitive treatment modality in patients with frozen shoulder. It results in significant and sustained relief of pain and also results in regaining full range of shoulder movements in patients with frozen shoulder and even in diabetic cases without any complications during or post-procedure.

\section{Conflict of interest}

None

\section{References}

1. Anton HA. Frozen shoulder. Can FAM Phys 1993;39:1773-7.

2. Lundberg B. The frozen shoulder. Acta Orthop Scand 1969;119(Suppl):5-59.

3. Reeves B. The natural history of the frozen shoulder syndrome. Scand J Rheumatol 1975; 4: 193-196.

4. Bridgman JF. Periarthritis of the shoulder and diabetes mellitus. Ann Rheum Dis 1972; 31: 69-71.

5. Uppal HS, Evans JP, Smith C. frozen shoulder: a systematic review of therapeutic options. World J Orthop 2015;6(2):2638 .

6. M Saltychev, K Laimi, P Virolainen, M Fredericson. Effectiveness of Hydrodilatation in Adhesive Capsulitis of Shoulder: A Systematic Review and meta analysis. Scand J Surg 2018;107(4)285-93.

7. S. Rymaruk, C. Peach. indication for hydrodilatation for frozen shoulder. EFORT open Rev 2017;2:462-8.

8. Rajendranath sinha, Priyes Patel, Nicky rose: Analysis of hydrodilatation as part of a combined service for stiff shoulder. SAGE journals 2017;9(3):169-77.

9. Satya Pal Sharma, Anders Baerheim. Adhesive capsulitis of the shoulder; treatment with corticosteroid, corticosteroid with distension a randomised controlled trial in primary care. $B M C$ Musculoskeletal Dis 2016;17:232.

10. Granville-Chapman J. Long-term results of hydro distension for frozen shoulder. Shoulder Elbow 2015;7:309-332.

11. Quraishi NA, Johnston P, Bayer J, et al. thawing the frozen shoulder. A randomised trial comparing manipulation under anaesthesia with hydrodilatation. J Bone Joint Surg Br 2007;89:1197-1200.

12. Smith CD, Hamer P and Bunker TD. Arthroscopic capsular release for idiopathic frozen shoulder with intra-articular injection and a controlled manipulation. J Shoulder Elbow Surg 2000;9:23-6.

13. Zwar RB, Read JW and Noakes JB. Sonographically guided glenohumeral joint injection. AJR Am J Roentgenol 2004;183:48-50.

14. Fareed DO, Gallivan WR Jr. Office management of frozen shoulder syndrome: treatment with hydraulic distension under local anaesthesia. Clin Orthop Relat Res 1989;242:177-83.

15. Papalia $\mathrm{R}$ et al: The use of hyaluronic acid in treatment of shoulder capsulitis: a systematic review. J Biol Regul Homeost Agents 2017.

16. Lin-Chien Lee, Fu-Kong Lieu, Hung-Lin Lee, Tao-Hsin Tung. Effectiveness of Hyaluronic Acid Administration in Treating Adhesive Capsulitis of the Shoulder: A Systematic Review of Randomized Controlled Trials. Biomed Res Int 2015, Article ID 314120 . 
17. Jacobs LGH, Barton MAJ, Wallace WA, Ferrousis J, Bunn NA, Bossingham DH. Intra-articular distension and steroids in the management of capsulitis of the shoulder. $B M J$ 1991;302:1498-501.

18. Clement RG. Frozen shoulder: long-term outcome following arthrographic distension. Acta Orthop Belg 2013; 79: 368-374.

19. Tveita EK, Tariq R, Sesseng S. Hydrodilatation, corticosteroids and adhesive capsulitis: a randomized controlled trial. BMC Musculoskelet Dis 2008;9:53.

20. Gavant ML, Rizk TE, Gold RE, Flick PA. Distension arthrography in the treatment of adhesive capsulitis of the shoulder. J Vasc Interv Radiol 1994;5:305-8.
21. Vad VB, Sakalkale D, Warren RF. The role of capsular distension in adhesive capsulitis. Arch Phys Med Rehabil 2003;84(9):1290-2.

How to cite this article: Subramanyam K, Sahini SC, Kumar S, Ampajwalam PR. Functional outcome assessment of frozen shoulder treated by distension hydrodilatation and viscosupplementation: A prospective study. Int J Orthop Rheumatol 2019;5(2):35-41. 